\title{
Modernização do "sertão" paranaense: atuação de Erasmo Pilotto e Diva Vidal na inovação de práticas pedagógicas (1940-1960)
}

\author{
Modernization of the "sertão" of Paraná: the action of \\ Erasmo Pilotto and Diva Vidal in the innovation of \\ pedagogical practices (1940-1960)
}

\author{
Modernización del "sertão" de Paraná: actuación de \\ Erasmo Pilotto y Diva Vidal en la innovación de \\ prácticas pedagógicas (1940-1960)
}

THAIS BENTO FARIA ${ }^{\mathrm{a}}$

AnALETE Regina SchelbaueR (iDb

\section{Resumo}

As iniciativas de Erasmo Pilotto e Diva Vidal, educadores que atuaram e influenciaram a administração escolar em um momento de expansão do ideário da Pedagogia da Escola Nova e das Escolas Normais no Estado do Paraná, são o tema central do presente estudo. Este artigo tem por objetivo demarcar a atuação destes sujeitos históricos e as estratégias delineadas para "modernizar" a prática pedagógica das escolas primárias rurais, por intermédio das Escolas Normais, da imprensa pedagógica, de documentos normatizadores e orientadores, entre as décadas de 1940 e 1960. Metodologicamente, neste estudo analisam-se as fontes documentais de época em diálogo com a historiografia da educação paranaense; portanto, emprega-se uma diversidade documental: a Revista de Pedagogia (1957-1966); a Regulamentação das Escolas Normais das Bases da Organização do Ensino Normal (1955); a Regulamentação e Organização do Ensino Normal (1958); o Relatório do

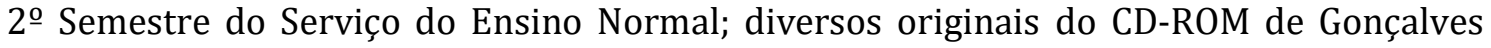
(2016) concernentes ao setor de Assistência Técnica do Serviço de Ensino Normal. Como principais resultados e considerações finais, identifica-se que Pilotto, com o caráter prescritivo da Revista de Pedagogia, enfatiza o processo de ensino individualizado e o uso do sistema de fichas. Diante do cenário de expansão, precariedade e também a busca por

\footnotetext{
a Universidade Estadual de Londrina (UEL), Londrina, PR, Brasil. Doutora em Educação, e-mail: thaisbentofaria@gmail.com

b Universidade Estadual de Maringá (UEM), Maringá, PR, Brasil. Doutora em Educação, e-mail: analeteregina@gmail.com
} 
inovação pedagógica, Vidal cria mecanismos para que o "moderno" se interiorize. Trata-se de iniciativas de sujeitos históricos que reverberaram em novas práticas, em sintonia com os novos tempos educacionais, a fim de "modernizar" o sertão paranaense.

Palavras-chave: História da formação de professores primários. Inovações pedagógicas. Erasmo Pilotto. Diva Vidal. Paraná.

\begin{abstract}
The initiatives of Erasmo Pilotto and Diva Vidal, educators who have acted and influenced the school administration in a moment of expansion of the ideas of the Pedagogy of the New School and of the Normal Schools in the State of Paraná, are the central theme of this present study. This article aims to highlight the performance of these historical individuals and their strategies to "modernize" the pedagogical practice of rural primary schools, through the Normal Schools, the pedagogical press, the normative and guiding documents, between the 1940s and 1960s. The method of this study consists in analyzing the documentary sources of the period, tracing a dialogue with the historiography of the education of Paraná, therefore, a documentary diversity is used: the Revista de Pedagogia (1957-1966); the Regulation of Normal Schools of the Foundation of the Normal Teaching Organization (1955); the Regulation and Organization of Normal Education (1958); Report of the 2nd Semester of the Normal Teaching Service; several originals of Gonçalves' CD-ROM (2016), documents concerning the Technical Assistance sector of the Normal Education Service. As main results and final considerations, it is identified that Pilotto, with the prescriptive feature of the Revista de Pedagogia, emphasizes the process of individualized teaching and the use of the files system. Facing a sctruture of expansion, precariousness and also the search for pedagogical innovation, Vidal creates mechanisms for the "modern" to internalize. These are initiatives of historical individuals that reverberated in new practices, in tune with the new educational times, in order to "modernize" the "sertão" of Paraná.
\end{abstract}

Keywords: History of primary teacher training. Pedagogical innovations. Erasmo Pilotto. Diva Vidal. Paraná.

\title{
Resumen
}

Las iniciativas de Erasmo Pilotto y Diva Vidal, educadores que actuaron e influyeron la administración escolar en un momento de expansión del ideario de la Pedagogía de la Escuela Nueva y de las Escuelas Normales en el estado de Paraná-Brasil, son el tema central del presente estudio. Este artículo tiene el objetivo de demarcar la actuación de estos sujetos históricos y las estrategias establecidas para "modernizar" la práctica pedagógica de las escuelas primarias rurales, por intermedio de las Escuelas Normales, de la prensa pedagógica, de documentos regulatorios y orientadores, entre las décadas de 1940 y 1960. Metodológicamente, en este estudio se analizan las fuentes documentales de época en diálogo con la historiografía de la educación de Paraná, por tanto, se emplea una diversidad documental: la Revista de Pedagogía (1957-1966); la Reglamentación de las Escuelas Normales de las Bases de la Organización de la Enseñanza Normal (1955); la Reglamentación y Organización de la Enseñanza Normal (1958); el Informe del $2^{\circ}$ Semestre del Servicio de la Enseñanza Normal; diversos originales del CD-ROM de Gonçalves (2016) concernientes al sector de Asistencia Técnica del Servicio de Enseñanza Normal. Como principales resultados y consideraciones finales, se identifica que Pilotto, con el carácter prescriptivo de la Revista de Pedagogía, enfoca el proceso de enseñanza individualizado y el uso del sistema de fichas. Ante 
el escenario de expansión, precariedad y también la búsqueda por innovación pedagógica, Vidal crea mecanismos para que lo "moderno" se interiorice. Se trata de iniciativas de sujetos históricos que repercutieron en nuevas prácticas, de acuerdo con los nuevos tiempos educacionales, a fin de "modernizar" el sertão (región agreste) de Paraná-Brasil.

Palabras clave: Historia de la formación de profesores primarios. Innovaciones pedagógicas. Erasmo Pilotto. Diva Vidal. Paraná.

\section{Introdução}

Em tempos em que o Paraná era percebido como "terra de oportunidades", como diria o governador do Estado Moysés Lupion (1947-1951 e 1956-1961), e se vivenciava um verdadeiro "espetáculo da prosperidade", como denominou, em 1952, o governador do Estado Bento Munhoz da Rocha Neto (1951-1955), este mesmo período trazia, paradoxalmente, inúmeros “desafios” (IPARDES, 1989).

Com intenso processo de (re)ocupação do território paranaense pela leva populacional que chegava atraída sobretudo pelo "Ouro Verde” (café) na região Norte e pela suinocultura e exploração de madeira no oeste e sudoeste, estes “desafios" também cresciam à medida que se criavam novos municípios: na década de 1950, representavam 25\% dos municípios; nos anos 1960, o percentual de cidades paranaenses cresceu 40\% (OLIVEIRA, 2001). Desde a década de 1940 instituíram-se órgãos como a Fundação Paranaense de Imigração e Colonização (1947) e o Departamento Administrativo do Oeste (1948) - depois transformado em Departamento de Fronteira, porque o governo buscava “[...] ter condições de atuar no sentido de estabelecer uma colonização disciplinada e dotar a região ocupada ${ }^{1}$ de uma infra-estrutura básica capaz de melhorar a sorte da população” (IPARDES, 1989, p. 32-33).

Compreende-se que, neste momento de intensa expansão populacional, com a criação de novas cidades, na tentativa de estabelecer uma "colonização disciplinada" e a modernização do campo, era preciso criar "infra-estrutura básica” e atingir o homem que ali habitava. Portanto, "modernizar" significava educar o campesino, ação que ocorreria se a escola primária chegasse até ele — e não qualquer escola, mas

\footnotetext{
${ }^{1}$ Embora a obra O Paraná reinventado: política e governo (IPARDES, 1989) utilize o termo "ocupada", optamos pela palavra (re)ocupada tal como diversos historiadores em estudos sobre determinadas regiões paranaenses ou acerca do Paraná: Cainelli (1994), Capelo (2000), Hoff (1991), Tomazi (1997), Schelbauer (2014) e Faria (2017).
} 
uma instituição sob a liderança de uma professora formada conforme as "modernas"2 concepções pedagógicas. No Estado do Paraná institucionalizaram-se e criaram-se “[...] políticas de expansão da escola primária na zona rural que fosse capaz de preparar homens e mulheres a resolverem seus problemas regionais e integrarem-se ao seu mundo rural” (SCHELBAUER, GONÇALVES NETO, 2013, p. 87), bem como expandiram-se os Cursos Normais Regionais entre 1940 e 1960, contribuindo com a interiorização da formação de professores paranaenses (FARIA, 2017).

O título deste artigo, como forma de provocação, traz a dicotomia da modernidade na palavra "sertão": refere-se a um Paraná com "vocação eminentemente agrícola” que, pela modernização do campo, pretende transformar o "sertão". Neste escrito, é compreendido como região interiorana, símbolo do atraso que, para se modernizar, contou com a educação, ação empreendida por estes dois educadores: Erasmo Pilotto e Diva Vidal.

O presente artigo objetiva demarcar a atuação de Erasmo Pilotto (1910-1992) e Diva Vidal (1911-2006), educadores que atuaram na administração escolar paranaense, que delinearam políticas educacionais, criaram normatizações e regulamentações de ensino com o intuito de modernizar a escola primária ao transformar a "moça do lugar", como nomeava Pilotto (1952), na sonhada professora normalista conhecedora dos "modernos" preceitos pedagógicos.

Este escrito traz uma breve apresentação destes educadores paranaenses e pontua as diferentes frentes de atuação de Erasmo Pilotto - quando ocupou o cargo de secretário da Secretaria da Educação e Cultura (SEC) do Paraná (1949-1951); na direção da Associação de Estudos Pedagógicos (AEP) para os Cursos Normais Regionais e do impresso pedagógico Revista de Pedagogia (1957-1966). Também destaca a presença de Diva H. Vidal, em especial quando esteve como chefe do Serviço de Ensino Normal (SEN), entre 1955 e 1960 — a produção de regulamentações, normativas, circulares e outros documentos com a finalidade de regulamentar e organizar as Escolas Normais em um cenário de intensa expansão; em especial, a

\footnotetext{
2 Inspirado em Mortatti (2000) que, ao escrever a história dos métodos de ensino da leitura e da escrita no Estado de São Paulo, emprega os termos "moderno" e "antigo", este artigo utiliza a expressão "moderno", por compreender a tensão entre estes opostos e como o "moderno" atribui "[...] um sentido distintivo e valorativo: melhor e revolucionário" (MORTATTI, 2000, p. 23).
} 
criação da Assistência Técnica no SEN e seu farto material destinado às Escolas Normais.

Para compor o cenário paranaense dos anos 1940 a 1960, foram fundamentais as obras do Instituto Paranaense de Desenvolvimento Econômico Social (1989) e de Oliveira (2001), associadas a outras pesquisas que tratam da História da Educação do Estado do Paraná, como Miguel (1992), Vieira (2001; 2006), Hervatini (2011), Schelbauer e Gonçalves Neto (2013), Schelbauer (2014), Gonçalves (2016), Faria (2017) e Silva (2018). Concernente a fontes documentais de época e produzidas no Estado do Paraná, analisamos a coleção da Revista de Pedagogia (1957-1966), com 20 números publicados em cinco volumes, disponíveis no Setor de Documentação Paranaense da Biblioteca Pública do Paraná; a Regulamentação das Escolas Normais das Bases da Organização do Ensino Normal (1955); a Regulamentação e Organização do Ensino Normal (1958a); o Relatório do $2^{\circ}$ Semestre do Serviço do Ensino Normal (VIDAL, 1958), que se encontra na biblioteca da Secretaria de Estado de Educação (SEED); diversos originais localizados e disponibilizados ao público em CD-ROM por Gonçalves (2016), confirmando que a socialização de fontes documentais possibilita o avanço na pesquisa em história da educação.

Das iniciativas de Erasmo Pilotto, com uma breve apresentação deste educador, sobretudo a análise da Revista de Pedagogia (1957-1966), em que era editor e diretor, o artigo direciona sua análise para as ações empreendidas por Diva Vidal, que assumiu a chefia do Serviço de Ensino Normal, teve que lidar com os desafios concernentes à expansão de instituições formadoras de mestres primários e criou estratégias de atuação - entre elas, a analisada neste escrito: os textos produzidos pela Assistência Técnica do Serviço de Ensino Normal.

\section{Desenvolvimento}

"Levamos a escola normal ao sertão"! Erasmo Pilotto, 1952.

Essa frase traduz o legado de Erasmo Pilotto durante o período em que ocupou o posto de secretário de Educação e Cultura do Paraná. Em suas narrativas acerca de incursões pelo interior do Estado, em $A$ educação é direito de todos, Pilotto (1952) evidencia os desafios sentidos na experiência como secretário da educação: um 
Paraná selvagem e árido que, em concomitância e contraditoriamente, era terra que transbordava esperança de fluxos (i)migratórios que almejam tempos melhores...

Professor, escritor, político e crítico, com vasta interlocução em diversas áreas, a epígrafe é de um sujeito histórico que ingressou na Escola Normal de Curitiba em 1927. Esteve envolvido em círculos de cultura de divulgação das ideias da Escola Nova (1927-1930), atuou como delegado do Paraná na V Conferência Nacional de Educação, de 1930 a 1980 participou “[...] das disputas teóricas e políticas do campo educacional paranaense e brasileiro" (VIEIRA, 2006, p. 3-5), foi liderança local e referência nacional quando houve a presença majoritária de renovadores em cargos da administração pública brasileira (VIEIRA, 2001).

De 1949 a 1951, como secretário da recém-criada SEC no Paraná, abriu muitas escolas primárias rurais, instituiu as Associações de Amigos da Escola, ampliou o acesso a cursos de formação de docentes via Curso Normal Regional, dentre outras ações enumeradas por Miguel (1992). Um entusiasta da Escola Nova, um educador comprometido com o progresso, em um momento em que havia apenas cinco Escolas Normais Secundárias em todo o Estado, circunscritas a Curitiba, Ponta Grossa, Paranaguá, Jacarezinho e Londrina. Na gestão de Erasmo Pilotto instalaram-se 19 Escolas Normais Regionais (ENRs), no ano de 1949 (MIGUEL, 1992; FARIA, 2017). E, no ano de 1951, esse número já atingia 24 cursos criados e instalados em diversas regiões do Estado. Diante do quadro de expansão retomamos a frase de Pilotto (1952): "Levamos a escola normal ao sertão”!

Mas, se no momento da criação e instalação dos primeiros e numerosos Cursos Normais Regionais, a figura de Erasmo Pilotto se fez presente na administração escolar, o período de expansão, quando se alcançam 70 Cursos Normais Regionais em 1958, foi Diva Vidal quem estava à frente do Serviço de Ensino Normal, delineando estratégias para que inovações pedagógicas chegassem aos novos e inúmeros cursos de formação docente, dentre eles a Escola Normal Secundária e a Escola Normal Regional (VIDAL, 1958).

\section{As iniciativas de Erasmo Pilotto}


Reconhecemos que a interiorização da Escola Normal trazia para as regiões mais ermas o "moderno", o "novo", por intermédio desta professora formada em espaços especializados na formação de professores, em um contexto em que o desafio era institucionalizar e expandir as escolas primárias, sobretudo, nas áreas rurais do interior e formar seus mestres.

A saída do educador da esfera política, em 1951, não retirou e nem minimizou sua atuação no campo educativo. Um exemplo disso foi a criação da Associação de Estudos Pedagógicos (1956-1970), que marcou a continuidade da intervenção no campo educativo e político do Estado, como assinala Silva (2018, p. 3).

\begin{abstract}
Após a saída da SEEC, Pilotto iniciou sua ação fora da esfera pública, ou melhor, tangenciando essa esfera, pois muitas das ações posteriores à SEEC, apesar de anunciadas como autônomas, apresentavam incentivos governamentais. Outro ponto de tangência com a esfera pública está no fato de que suas ações e parte de suas obras se dedicaram a discutir a educação pública estatal, repensando os sistemas de ensino tanto no contexto nacional como no latino-americano, demonstrando a continuidade de sua intervenção no campo educacional e político com a criação da AEP.
\end{abstract}

A Associação tinha como finalidade o desenvolvimento de metodologias que pudessem ser aplicadas nas escolas primárias do Estado e a realização de pesquisas educacionais, muitas das quais foram publicadas na Revista de Pedagogia (PUGLIELLI, 1996 apud HERVATINI, 2011; SILVA, 2018).

É neste contexto que destacamos a atuação de Pilotto como editor e diretor da Revista de Pedagogia, impresso pedagógico de cunho associativo, publicado entre os anos de 1957 e 1966 como órgão da Associação de Estudos Pedagógicos para os Cursos Normais Regionais.

A coleção analisada contemplou 20 números $^{3}$ publicados em cinco volumes entre maio de 1957 e fevereiro de 1966, além de seis suplementos, que podem ser localizados no Setor de Documentação Paranaense da Biblioteca Pública do Paraná. Não encontramos até o presente momento informações sobre a continuidade da publicação do periódico para além do ano de 1966.

Sua finalidade inicial foi inscrita no primeiro número da publicação ao tecer considerações sobre as condições precárias do ensino primário no meio rural.

\footnotetext{
${ }^{3}$ Nosso levantamento documental constatou a afirmação feita por Silva (2018, p. 7): a coleção completa possui 22 números. "Destes, não foram encontrados os exemplares de números 3 e 4 do volume 4 da revista, que possivelmente foram publicados entre 1960 e 1962 ".
} 
Lançando um olhar sobre o ensino primário no nosso meio rural, notamos que os resultados são realmente dramáticos. E resolvemos dirigindo-nos às professoras dos Cursos Normais Regionais, encarar o problema de frente, tentando resolvê-lo, analisando a realidade do nosso meio rural, sem sentimentalismos nem pessimismos excessivos (PILOTTO, 1957, p. 1).

A partir do argumento de que os resultados satisfatórios do ensino primário no interior estavam a depender do trabalho que seria feito pelas professoras que frequentavam os Cursos Normais Regionais, destaca a "missão" da Revista de Pedagogia: "oferecer um preparo prático aos professores em formação pelos Cursos Normais Regionais dos quais dependem o êxito do ensino primário no meio rural paranaense" (PILOT'TO, 1957, p. 1).

Com essa tônica, a revista prescreve, em seu primeiro número, práticas pedagógicas sobre o ensino inicial da leitura, da multiplicação e da divisão por meio do processo metodológico baseado na individualização do ensino. No Quadro 1, podemos acompanhar as temáticas correntes ao longo da publicação do periódico.

Quadro 1 - Temáticas da Revista de Pedagogia

\begin{tabular}{|c|c|c|}
\hline № da revista & Período & Temáticas \\
\hline Vol. I, n 1 & Maio/1957 & $\begin{array}{l}\text { O ensino inicial da leitura; multiplicação e divisão por } \\
\text { meio da individualização do ensino }\end{array}$ \\
\hline Vol. I, n. 3 & Agosto/1957 & Individualização do ensino \\
\hline Vol. II, n. 1 & Fevereiro/1958 & $\begin{array}{l}\text { Individualização do ensino; intercâmbio de } \\
\text { experiências - Escola Rural de Madeirit }\end{array}$ \\
\hline Vol. II, n. 2 & Abril/1958 & $\begin{array}{l}\text { A produção agrícola brasileira; o cooperativismo; o } \\
\text { significado social dos seguros; os transportes e sua } \\
\text { importância; os impostos como contribuição de valor } \\
\text { social }\end{array}$ \\
\hline $\begin{array}{l}\text { Vol. II, n. } 3 \text { e } \\
4\end{array}$ & Junho e agosto/1958 & Individualização do ensino \\
\hline Vol. II, n. 5 & Outubro/1958 & Individualização do ensino \\
\hline Vol. III, n. 1 & Fevereiro/1959 & $\begin{array}{l}\text { Ensino de História nos Cursos Normais Regionais do } \\
\text { Paraná }\end{array}$ \\
\hline Vol. III, n. 2 & Abril/1959 & Jardins de Infância \\
\hline $\begin{array}{l}\text { Vol. III, n. } 3 \text { e } \\
4\end{array}$ & Junho e agosto/1959 & Programas experimentais para o curso primário \\
\hline Vol. III, n. 5 & Outubro/1959 & $\begin{array}{l}\text { Ensino e educação política para a escola média; } \\
\text { ensino de frações }\end{array}$ \\
\hline Vol. IV, n. 1 & Março/1960 & $\begin{array}{l}\text { Ensino do desenho; conversação instrutiva; ensino da } \\
\text { aritmética }\end{array}$ \\
\hline Vol. IV, n. 2 & Maio/1960 & $\begin{array}{l}\text { Problema nacional do analfabetismo; áreas sociais } \\
\text { desigualmente desenvolvidas pedem soluções } \\
\text { pedagógicas diferenciadas; a educação em sociedades } \\
\text { em desenvolvimento }\end{array}$ \\
\hline Vol. IV, n. 5 & Novembro/1962 & $\begin{array}{l}\text { Um debate teórico com fundamento na apreciação da } \\
\text { Lei de Diretrizes e Bases da Educação Nacional; plano } \\
\text { Langevin de reforma do ensino francês; ciência, } \\
\text { educação e técnica; o problema do inconsciente }\end{array}$ \\
\hline
\end{tabular}




\begin{tabular}{|l|l|l|}
\hline Vol. V, n. 1 & Fevereiro/1963 & $\begin{array}{l}\text { Em torno do problema da escola média; o estudo da } \\
\text { história; pela unidade da escola }\end{array}$ \\
\hline Vol. V, n. 2 & Fevereiro/1965 & $\begin{array}{l}\text { Fatos e expectativas novos na educação na América } \\
\text { Latina; o problema epistemológico na pedagogia } \\
\text { contemporânea }\end{array}$ \\
\hline Vol. V, n. 3 & Setembro/1965 & $\begin{array}{l}\text { A crise do ensino médio brasileiro; economia e } \\
\text { educação; Estrutura de uma Escola Normal }\end{array}$ \\
\hline Vol. V, n. 4 & Fevereiro/1966 & $\begin{array}{l}\text { Soluções simples e generalizáveis na educação; } \\
\text { retorno ao tema da Educação Nova; a educação e o } \\
\text { desenvolvimento nacional }\end{array}$ \\
\hline
\end{tabular}

Fonte: Elaborado pelas autoras.

Como se pode observar, os números publicados no decorrer dos anos de 1957 e 1958 incidem sobre o preparo prático para atuação dos professores, com ênfase no ensino inicial da leitura, da composição escrita e da multiplicação, bem como a orientação para o uso do sistema de fichas para a individualização do ensino, por séries. Essa orientação é retratada pela revista como a mais adequada ao ensino nas Escolas Isoladas das áreas rurais.

Sendo tão frequente, entre nós, o regime das escolas isoladas, isto é, das escolas que, numa só sala de aula e com um só professor, têm alunos da $1^{\underline{a}}$, da $2^{\underline{a}}$ e da $3^{\underline{a}}$ série (e às vezes ainda da $4^{a}$ série), um regime de ensino individualizado, em que o aluno trabalhe por sua conta, mediante indicações bem assentadas, pode representar uma das mais eficazes soluções para o grave problema em que se encontra o mestre naquelas escolas, tendo de dar aula e atender a classes tão diversas, - problema em que fracassam, tantas vêzes, mesmo professores bem preparados (PILOTTO, 1957, p. 1).

A revista manterá a ênfase no processo de ensino individualizado, como uma saída ao problema da organização do ensino primário nas Escolas Isoladas do meio rural. Para tanto, passa a retratar sob essa ótica o ensino inicial da leitura, da acentuação ortográfica, das frações decimais, da aritmética, da divisão, das ciências físicas, da composição textual, bem como outros aspectos relacionados à organização pedagógica da escola primária.

As propostas apresentadas para o ensino da leitura, aritmética, multiplicação e divisão, contempladas nos primeiros anos da revista, baseiam-se na metodologia de fichas individualizadas de Dottrens ${ }^{4}$ que, de acordo com Silva $(2018$, p. 8) “[...] foram

\footnotetext{
${ }^{4} \mathrm{O}$ sistema de fichas ou cartas (cartes) de Dottrens é uma das principais características da proposta de Erasmo Pilotto "[...] a orientação dada à AEP se baseou na interlocução de Pilotto com a obra do pedagogo suíço, Robert Dottrens, cuja aplicação o intelectual havia observado pessoalmente na Europa, em viagem realizada em 1951" (PUGLIELLI, 1996, apud SILVA, 2018, p. 5).
} 
realizadas ou observadas pelas colaboradoras de Pilotto, e, apesar de se destinarem às escolas isoladas, as atividades foram realizadas em grupos escolares da capital ou urbanos".

A metodologia seria uma aspiração de Pilotto e comporia um "sistema de controle do professor para o aluno como também um controle sobre o trabalho do professor" para proporcionar "[...] a cada criança o ensino adequado à sua capacidade de aprender, sendo extremamente útil, especialmente no contexto das escolas isoladas, e facilmente utilizável por professores com carência de formação especializada” (SILVA, 2018, p. 8).

Tal metodologia foi observada nos registros documentais de duas Escolas Normais Regionais do interior paranaense por meio da valorização das práticas de leitura no ensino primário com a finalidade de "[...] desenvolver tanto nas crianças quanto nos normalistas um bom aperfeiçoamento da leitura, para serem excelentes leitores e grandes narradores" (HERVATINI, 2011, p. 161).

Os registros encontrados nas práticas pedagógicas que as normalistas realizavam para a docência nas Escolas Isoladas, com as denominadas fichas de leitura, oferecem indícios de que estas foram largamente exploradas. As fichas eram elaboradas pelas alunas e alunos das Escolas Normais Regionais e utilizadas tanto na alfabetização quanto para prática de leitura no ensino primário.

O estudo constatou que as normalistas da Escola Normal Regional Pestalozzi se dispunham a doar as fichas de leitura e outros materiais confeccionados e utilizados nas atividades realizadas nas Escolas Isoladas para as professoras regentes das escolas primárias, conforme as orientações da Associação de Estudos Pedagógicos: “[...] dia 29 de agôsto [de 1960 quando] os alunos da $4^{\text {a }}$ série ofertaram aos professôres do município a série de fichas destinadas ao ensino da leitura" (COLÉGIO ESTADUAL ALBERTO SANTOS DUMONT, 2010, Livro Ata n. 1, p. 11, apud HERVATINI, 2011, p. 161).

Tal prática, segundo a pesquisadora, ocorria tanto pelo despreparo de suas professoras em relação às novas metodologias de ensino quanto pela falta de condições materiais das Escolas Isoladas, sobretudo aquelas localizadas nas zonas rurais de difícil acesso ou com poucos recursos (HERVATINI, 2011). 
A questão ressaltada pela autora encontra ressonância na narrativa de Silva (2018) sobre o sistema de individualização do ensino proposto por Pilotto em sua atuação junto à Associação de Estudos Pedagógicos.

\begin{abstract}
Nesse sentido, no sistema de individualização transparece a posição de Pilotto sobre os papéis dos professores, aqueles que aplicariam as fichas e aqueles que as produziriam, ou os professores que seriam a liderança educacional e aqueles responsáveis pelo trabalho direto na escola. [...] aqueles que estariam ligados à rotina escolar, aplicando a metodologia criada pelos primeiros. (SILVA, 2018, p. 5).
\end{abstract}

De acordo com as informações descritas, a Revista de Pedagogia prescreveu práticas pedagógicas baseadas na individualização do ensino e na utilização do sistema de fichas nos anos iniciais de publicação do periódico. Considerando os indícios dessa prática nas Escolas Normais Regionais, como aponta o estudo de Hervatini (2011), podemos inferir, mesmo não tendo dados de circulação da revista, que o periódico tenha circulado em tais instituições, como parte do projeto de interiorização desses cursos, dando indícios de que o impresso pedagógico foi uma das estratégias de Pilotto, por meio da AEP, para levar práticas inovadoras ao “sertão".

Além dessa temática, ganham expressão as Escolas Isoladas experimentais, vinculadas aos Cursos Normais Regionais, o intercâmbio e o relato de experiências entre normalistas e as escolas do meio rural, os programas experimentais para o curso primário, os problemas da produção agrícola brasileira, a temática do cooperativismo, dos transportes.

Nos últimos números da década de 1950, a revista insere uma seção intitulada "Através da Impressa" por meio da qual publica resenhas de artigos e capítulos de livros relacionados à formação de professores. Os materiais compilados na seção citam fontes como: Revista L'Année Psychologique (1940-1941); Programa de atividades de los jardines de infantes, por Smith Hill; El problema epistemológico em la pedagogia contemporanea, publicado no Caderno 2 da Escuela de Pedagogia e Psicologia (1960) por Otília Celia de Montoya; artigo de J. E. Heyde publicado na revista pedagógica alemã Bildung und Erziehung (1957), dentre outros.

A partir da década de 1960, a discussão incide sobre o problema nacional do analfabetismo e a contribuição da AEP acerca da temática do Plano Nacional de Combate ao Analfabetismo, além de temas relacionados à educação em sociedades em desenvolvimento, economia e educação, Educação Nova, relação entre ciência, 
educação e técnica, bem como aos debates em torno dos fundamentos para apreciação do projeto de Lei de Diretrizes e Bases da Educação Nacional e do novo ensino médio. Neste sentido, destacamos os títulos de três artigos escritos por Pilotto e Kolodi, respectivamente: "Um plano nacional de combate ao analfabetismo" (PILOTTO, 1960b); “A educação em sociedades em desenvolvimento” (PILOTTO, 1960a) e "Áreas sociais desigualmente desenvolvidas pedem soluções pedagógicas diferenciadas" (KOLODI, 1960).

O artigo de Kolodi (1960) dirige-se, primeiramente, às diretoras dos Cursos Normais Regionais do Paraná, com o apelo de que as alunas contribuíssem para o desenvolvimento das "escolinhas isoladas" das zonas rurais, tendo em vista o grande número de reprovações. O artigo traz um documento intitulado "Instrução para a professora de Didática e Prática de Ensino”, no qual consta um guia metodológico contendo 11 fichas para o ensino de leitura, a partir da Cartilha do Povo, de Manoel Bergstron Lourenço Filho. A segunda parte é conduzida aos prefeitos municipais, em nome da Associação de Estudos Pedagógicos, para que os mesmos promovam reuniões com as professoras primárias, nas quais as normalistas e as inspetoras de ensino municipal, previamente preparadas pela AEP, possam ensinar "os processos preconizados pela Associação, às professoras reunidas. Ensine-os até o ponto de que cheguem a ser dominados como uma rotina" (KOLODI, 1960, p. 48).

Nas diversas matérias que compuseram o periódico, Erasmo Pilotto manteve frequente sua contribuição. Além do educador, contribuíram as professoras ${ }^{5}$ : Rosa Kolody, Nahir Fernandes Cavallin, Maria Eulina dos Santos Schena, Leda Grein Santos, Ailema Luvison Franck, Franciliza X. Valente, Sara Sartori, Ivete Torres Ribeiro, Odele de M. Cid, Olga Kolody e a normalista Lúcia Rysicz, dentre outras.

Ao procurar nos registros do tempo passado as marcas impressas pela Revista de Pedagogia, encontramos vestígios de um caminho percorrido pelos educadores de um tempo, na tentativa de criar estratégias para a formação de professores no meio rural. Com isso, observamos que a "[...] imprensa, sem dúvida, tem se configurado como uma dessas novas fontes e possibilitado, por meio de diversos olhares, a constituição do retrato de um tempo" (SCHELBAUER, 2007, p. 7).

\footnotetext{
${ }^{5}$ Silva (2018) considera que o corpo de colaboradores da revista era constituído por professoras que haviam sido alunas de Pilotto e que também participavam da AEP.
} 


\section{As iniciativas de Diva Vidal}

Permeados de escritos de uma vida prática e atrelada ao ofício de educadora, atuante no período de expansão da escola primária rural, das Escolas Normais Regionais e Secundárias e também de expansão de um ideário, o escolanovista, poderíamos empregar os diversos avisos, circulares, regulamentos, relatórios e demais documentos para apresentar Diva H. Vidal (1911-2006). Estes escritos ratificam o intenso trabalho para a organização, padronização, regulamentação e modernização das práticas pedagógicas dos cursos de formação docente primário paranaense.

Diva Vidal-Memória viva da educação, trata-se da única obra que se aproxima da trajetória desta mulher "pequena e frágil" que, aos 85 anos de idade, recebia homenagens pela vida dedicada à educação. Desde os 17 anos lecionava educação física em Paranaguá, sua terra natal. Afastou-se da ginástica e dos jogos, depois ministrou aulas de matemática no Ginásio da Escola Normal Dr. Caetano Munhoz da Rocha e no Colégio Estadual José Bonifácio. No fim da década de 1940, mudou-se para Curitiba e atuou como docente no Ginásio Paranaense. (PARANÁ, [1997?]). Entre 1955 e 1961, foi chefe do Serviço de Ensino Normal e interessa a este artigo o tempo em que esteve à frente do SEN, poucos anos dos muitos dedicados ao magistério, por ser um momento em que este órgão lidava com a expansão vertiginosa e desafiadora de instituições de formação de professores primários.

O ensino normal até 1955 era atendido junto ao ensino médio e superior, com uma única chefia. A partir desta data, subordinado ao Departamento de Educação, assinala Vidal (1958) que, na prática, o SEN teve autonomia na organização do trabalho pedagógico das Escolas Normais. Após a década de 1960, com a criação das Inspetorias Regionais de Ensino e uma organização mais descentralizada da educação, a relação entre o SEN e as Escolas Normais mudou substancialmente, confirma Faria (2017).

Entre 1955 e 1960, Vidal conviveu com o dilema de expandir as Escolas Normais e, simultaneamente, oferecer diretrizes gerais e garantir que a inovação chegasse a instituições interioranas de formação de professores, criou estratégias, dentre elas a criação do setor de Assistência Técnica para orientar “[...] quanto a 
pesquisas, organização de planos de aulas, pontos de diferentes disciplinas que forem difíceis de organizar, principalmente, nas Escolas do interior, onde as bibliotecas ainda são incipientes" (PARANÁ, [1958 ou 1959a]). Na ausência de bibliotecas, este setor foi encarregado de veicular "modernas" ideias educacionais e, de certa forma, padronizar práticas pedagógicas.

Paralelo à organização de textos pelas Assistentes Técnicas do Serviço de Ensino Normal, o SEN insistia que cada Curso Normal instituísse sua biblioteca. Vidal frisa a necessidade de campanhas, que não eram concebíveis escolas e, muito menos a Escola Normal, sem este espaço, haja vista que "[...] os alunos tem que pesquizar e realizar trabalhos que precisam de consultas". A chefe do SEN sugeria que se pedisse colaboração ao Instituto Nacional do Livro, se organizassem festividades, cuja renda fosse utilizada na compra de obras etc. (PARANÁ, 1958h).

A insistência e a recorrência do tema em circulares e orientações do SEN estavam em consonância com dois documentos que normatizaram a Escola Normal na década de 1950: a Regulamentação das Escolas Normais das Bases da Organização do Ensino Normal do Estado do Paraná de 1955 e, depois, a Regulamentação e Organização do Ensino Normal do Estado do Paraná de 1958. (PARANÁ, 1955; PARANÁ, 1958a). Em ambas, a biblioteca e as "instituições escolares" conquistaram capítulo à parte, com seus respectivos "meios complementares educativos" associação de pais e mestres, agremiações de alunos e ex-alunos, clubes, cantinas escolares, caixas, museus, cooperativas, cinemas, rádios etc.

Mesmo considerando a biblioteca como uma das "entidades indispensáveis à vida escolar" e, inclusive, nas regulamentações de 1955 e 1958 destaca-se que seria constituída de obras de cultura geral e especializada, fornecidas pelo Estado, adquirida pela escola ou por doações, outros documentos que circularam no interior das Escolas Normais indicam que, na prática, a responsabilidade por sua constituição era da própria escola e comunidade local: com recursos financeiros do poder municipal, com a criação da Associação de Amigos nas Escolas Normais e da Associação de Pais e Mestres nas Escolas de Aplicação — estratégias que, de algum modo, isentavam o Estado do Paraná desta responsabilidade (FARIA, 2017).

Frente ao cenário de expansão, de escolas de formação docente e de um modelo pedagógico, em 1958, quando foi criado o setor de Assistência Técnica, este 
atendia todas as Escolas Normais. Considerando que a maior parte das instituições formadoras de professores era de Cursos Normais Regionais, como demonstra Faria (2017), lidava com diversos problemas: falta de local para acomodar as turmas, dificuldades de prover material permanente e de expediente. E, diante da situação, contava com a ação voluntária de seus funcionários, da administração municipal e da comunidade local. Dispor de espaço para biblioteca e livros para equipá-la era um desafio e situação remediada com a criação da Assistência Técnica, disseminando o que havia de mais "novo" e "moderno" no campo educativo.

Gonçalves (2016), ao analisar a pauta de discussão das reuniões mensais do Curso Normal Regional de Cianorte, entre 1957 e 1962, aponta que o assunto de maior destaque era a leitura e discussão de documentos oficiais.

\begin{abstract}
0 assunto mais mencionado diz respeito à discussão dos documentos enviados pelos órgãos aos quais a escola estava submetida. As orientações eram lidas e discutidas antes de se abordar os assuntos referentes à formação pedagógica ou ao cotidiano da escola, e, quando os documentos não chegavam, as atas registram a preocupação com o fato de não haver instruções, o que denota uma grande preocupação em seguir as instruções dos órgãos superiores (GONÇALVES, 2016, p. 125).
\end{abstract}

Desta forma, ao analisar parte do produzido pelo setor de Assistência Técnica, identificamos o que era objeto de discussão e o material que orientava as Escolas Normais paranaenses. Em alguns textos encontramos apenas fragmentos, que estão assinalados com *. Foram produzidos pela Assistência Técnica do SEN nos anos de 1958 e 1959 e informamos o ano exato quando a fonte documental o especifica.

Considerando que estes escritos eram substitutos das bibliotecas na maior parte das Escolas Normais e instrumento de análise em reuniões mensais, comecemos por Orientação sôbre as reuniões mensais, de Armanda Sabino Lopes, em que destaca que estes encontros "não podem ater-se exclusivamente à discussão de questões de cunho meramente administrativo", como em muitas escolas. Lopes apresenta diversas possibilidades e formas de abordar as questões pedagógicas: orientações quanto às atividades de classe, à pesquisa dos alunos (em livros, publicações, inquéritos e pesquisas de ordem social); orientações acerca da relação professor-aluno para conseguir o "melhor ajustamento às experiências da vida escolar"; discussão sobre alunos problemas; questões referentes à orientação técnica à Escola de Aplicação. (PARANÁ, [1958 ou 1959d]). 
Em um período de expressiva expansão e busca por padronização do conteúdo programático, preocupavam-se com o Plano de curso e de aula*, sendo este o tema de um dos textos produzidos pelo setor, escrito pela professora Ivete T. Ribeiro. Em sua introdução, traz uma citação de Pilotto e assinala que os professores se queixam da ineficácia e inexequibilidade dos programas, todavia trabalham minúcias, desconsideram o essencial, agem improvisamente, gerando disparidade entre as turmas e no cumprimento do programa, prejudicando os alunos e oferecendo um "conhecimento superficial que pouco lhes valerá". Emprega estes argumentos com o propósito de que o professorado elabore seu plano de curso, adequando-o aos alunos a que se destina, ao programa em vigência, ao número de aulas e ao material didático disponível (PARANÁ, [1958 ou 1959e]).

Três textos tratam sobre programas: Considerações sôbre o caráter prático dos programas de Português e Matemática - E.N.R.* (1958), Orientação geral sôbre parte do programa de Música das Escolas Normais Regionais (1958) e Programa de Higiene, Ciências Físicas e Naturais (1959). Os dois primeiros são de autoria de Armanda Sabino Lopes e o terceiro, de Chloris Casagrande Justen. O primeiro responde inúmeras solicitações das Escolas Normais Regionais a fim de que o programa de português e matemática tenha um caráter mais prático. $\mathrm{O}$ escrito apenas objetiva dar mais clareza, dividir em unidades, especificar tópicos, indicar fontes de consultas. Entretanto, cita a portaria $\mathrm{n}^{\mathrm{o}} 42$ de 1950, considerada pelo professor Anísio Teixeira um trabalho de grande valor, por isso fora distribuída a todos os Estados brasileiros, como sugestão e orientação, detalhando objetivos gerais e especiais, orientação metodológica, bibliografia e muitas sugestões práticas (PARANÁ, 1958c).

Em resposta a como cumprir o programa de música nos Cursos Normais Regionais no que se refere a "audição fonográfica de Bach, Mozart e Beethoven”, no segundo texto, Lopes enumera uma série de sugestões: realização de palestra preparatória, à guisa de motivação; trabalho de pesquisa sobre a vida e obra do autor, como forma de "trabalho prático", e uso de toca-discos. No entanto, o próprio setor reconhece que a maioria das escolas não possuía discoteca, nem toca-discos, e sugere como possibilidade a audição ao piano, o empréstimo de um aparelho, a realização de campanha para aquisição do material necessário, por intermédio do Centro de Cultura, patrocinar ou conseguir patrocínio de concertos. Em suma, apresenta 
diversas alternativas práticas, desobrigando o Estado de prover a escola de material necessário para a concretização de um método de ensino que requeria recursos didáticos específicos (PARANÁ, 1958d).

Sobre o terceiro texto - Programa de Higiene, Ciências Físicas e Naturais (1959) - embora não haja qualquer disciplina com esta nomenclatura na Escola Normal Regional, tampouco na Escola Normal Secundária, interessa sua análise porque ratifica, mais uma vez, a preocupação com um ensino mais prático e a busca deste setor por mostrar possibilidades para as instituições formadoras de professores primários. A Assistente Técnica, a cada unidade do programa, inseria a palavra "prática" na sequência, oferecendo sugestões: realização de inquéritos sobre hábitos e higiene local e considerações sobre os resultados; campanhas de higienização; divulgação dos efeitos da vacinação; construção de latrinas com uso de material simples como caixotes; construção de filtros feitos de tijolos, cascalhos, areia grossa e fina; clubes da saúde; comandos de higienização na região e etc. (PARANÁ, 1959b).

A mesma tônica se identifica em Material funcional nas aulas práticas. Matéria de Didática*. A professora Ivete T. Ribeiro referencia a Revista de Educação e Cultura, da SEC de Pernambuco, que trata do Seminário de Escola Primária, 1957, que aconteceu em Recife. O evento aponta a responsabilidade das Escolas Normais na formação pedagógica de seus alunos e lamenta que os professores fiquem "perdidos nas bibliotecas, estudando aspectos pedagógicos em têrmos teóricos”. O teor do escrito sugere que a biblioteca, espaço idealizado e desejado pelas escolas naquele momento, estava a serviço do ensino na medida em que tratasse do aspecto prático, de compreender a realidade concreta das escolas primárias (PARANÁ, [1958 ou 1959c]).

O apelo pela prática também se observa em Como conseguirpontualidade dos alunos nos trabalhos práticos (1958), de Armanda Sabino Lopes. A regulamentação das Escolas Normais das Bases da Organização do Ensino Normal (1955) definia que mensalmente cada matéria creditaria ao aluno:

[...] uma nota de aplicação que resultará da assiduidade, pontualidade, aproveitamento nas chamadas e exercícios práticos, trabalho obrigatórios ou espontâneos, de espírito de iniciativa, de capacidade de estudo e pesquisa independentes [...] (PARANÁ, 1955, p. 6).

Entretanto, a regulamentação de 1958 exclui este trecho. Inferimos que esta obrigatoriedade gerava uma sobrecarga de trabalhos práticos e a necessidade de lidar 
com problemas como a "pontualidade". Lopes esclarece que não há "receita" sobre o assunto, que a pontualidade na entrega de trabalhos práticos depende de uma série de fatores de ordem objetiva e subjetiva. Dentre eles, o tempo necessário para a confecção do trabalho, a orientação prévia do professor, o grau de dificuldade compatível com a capacidade e o nível dos alunos e, como problema persistente, a presença de material bibliográfico (PARANÁ, 1958b). Em relação a este assunto, Lopes pontua que:

Tratando-se de escolas situadas em localidades pobres de livrarias e bibliotecas, é preciso que o professor atenda à dificuldade de conseguir estas fontes de consulta; é preciso que ele indique à direção da biblioteca da escola, livros e publicações a serem adquiridas; que oriente os alunos sôbre onde e como conseguir estas fontes até mesmo a título de empréstimo, etc. (PARANÁ, 1958b).

$\mathrm{Na}$ busca por uma escola mais ativa, que modificasse a relação professor-aluno, em que o estudante assumisse o papel de agente no processo educativo, criaram regulamentações, no limite encontrado no âmbito prático; suspenderam-nas; consultaram a Assistência Técnica a fim de oferecer possibilidades. Trata-se do apelo para a prática, que se transformou, inclusive, em um item a ser avaliado. Todavia, estes denominados trabalhos práticos precisavam, contraditoriamente, de suporte de pesquisa; onde encontrá-los?

Para inovar as práticas pedagógicas, deslocar o tradicional lugar ocupado na aprendizagem pelo professor e aluno, intentavam outras metodologias. Esta é a finalidade de Orientação sobre Estudos Dirigidos (1958), de Nely F. Holzmann. Partindo da premissa de que "se o estudo não for bem orientado e dirigido, torna-se um obstáculo para o bom ensino", apresenta o método criado pelo professor V. F. Thayer, da Universidade de Ohio, que mostra "as vantagens do ensino individual com a instrução em grupo”. O método era dividido em fases: escolha da tarefa; separação do material; plano de desenvolvimento; o estudo dirigido feito individualmente com leituras especiais, experiências, exercícios formais, mapas, entre outros; finalização com a reunião em grupo e com a discussão, sob a direção do professor. Orienta que o "exercício nunca deverá ser imposto como obrigação, mas primeiro criar a necessidade do aprendizado em questão", "estimulando o trabalho escolar por meio de idéias, valores e interesses que se possa formar no aluno" ou "utilizando como motivo a rivalidade ou emulação" porque "não há estudo possível sem motivação 
suficiente. A técnica da motivação é fator importantissimo no estudo dirigido”. No detalhamento das orientações, reitera que não se pode inibir a iniciativa e a espontaneidade dos alunos com instruções demasiadamente minuciosas (PARANÁ, 1958f).

Embora não cite Aguayo (1952), as ideias veiculadas e a menção a dois professores - F. S. Breed e V. F. Thayer, da Universidade de Ohio - em ambos os textos explicitam que estas orientações pautaram-se na obra de Aguayo (1952), que critica a educação racionalista em que o docente prevê e dirige tudo e não se preocupa com o interesse do aluno. O autor advoga a favor de uma educação que se orienta pelos estudos da psicologia infantil.

Fatores importantes da evolução da didática contemporânea têm sido também o estudo sistemático da criança, que atualmente se realiza em um grande número de escolas, laboratórios e clínicas e os notáveis progressos que tem feito a psicologia desde a sua transformação em ciência de caráter experimental (AGUAYO, 1952, p. 5).

Como um bom escolanovista, Aguayo (1952, p. 152) considera a classe “[...] não mais uma sala em que a criança ouve as lições e sim uma oficina ou um laboratório em que a criança trabalha, discute, estuda e joga". Ao propor o estudo dirigido, demonstra que segue a premissa: "ensina o escolar a aprender por si mesmo" (AGUAYO, 1952, p. 152, grifo do autor). Em sintonia com esta metodologia de trabalho também se encontra o Trabalho em grupo* (1959). Nele, Mirian Schruber recomenda que a técnica mais perfeita de escolha do grupo é a aplicação do Sociograma, pois mostra a estrutura social da classe e o lugar do indivíduo no grupo. Orienta, passo a passo, como se deve proceder tecnicamente e analisar os dados coletados. Lembra que a tarefa será suficientemente motivada se despertar a curiosidade e o desejo de aprender. Pontua que em trabalhos em grupo é preciso a realização de pesquisas bibliográficas, excursões, visitas a fábricas, relatórios, resumos, composições, levantamentos estatísticos, desenhos, maquetes etc. Na referência bibliográfica constam "modernas" ideias e obras: Didática da Escola Nova (A. M. Aguayo), Os Métodos Pedagógicos (Guy Palmade) e aulas do Curso de Especialistas em Educação para a América Latina. (PARANÁ, 1959c).

Em Informações sôbre a organização dos Grêmios Escolares*, já no início do texto, Lopes recomenda a leitura de Prática de Escola Serena (Pilotto) e declara que a temática 
tem relação direta com a Pedagogia Nova (PARANÁ, [1958 ou 1959b]). No escrito Orientações sôbre — Profilaxia da cola — Escolas Normais Regionais e Secundárias* (1958), em resposta a uma professora sobre como agir para combater a "cola" nos Cursos Normais, Armanda Sabino Lopes escreve algumas considerações. Sobretudo, ela destaca que "o maior culpado é o professor" porque "no curso primário ensinava as resposta às perguntas", "ensinava mal e elaborava questões difíceis de serem guardadas, questões que apelavam à memória quase sempre incidindo sôbre, datas, extensões, fórmulas, etc.". Portanto, acusa a “velha” metodologia de trabalho docente como a motivadora deste problema (PARANÁ, 1958g).

Para finalizar esta análise preliminar, encerramos com os textos Orientação para recuperação de alunos das Escolas Normais* (1958) e Conceito de Orientação Educacional e valor da mesma nos Cursos Normais (1959). O primeiro, diante do problema da recuperação dos alunos com baixo rendimento escolar nas Escolas Normais, a inspetora estadual Maria de Lourdes M. Chaves assinala a necessidade da investigação para examinar as causas do rendimento deficiente, haja vista que no Paraná não havia nada de positivo no que concerne ao "atendimento às diferenças — individuais e cumpre a função de permitir, um progresso mais real e significativo para cada estudante, segundo suas possibilidades e ritmo de aprendizagem". Em seguida, salienta que, de todos os Estados brasileiros, o "mais adiantado" no assunto era o Rio Grande do Sul. Para as Escolas Normais paranaenses, orienta a instituição de "horas suplementares de trabalho na própria escola, dentro e fora do horário escolar, ou mesmo, em hora pré-determinada, na residência do professor da matéria em que desejam ser recuperados", bem como que o problema fosse resolvido mediante aulas extras, que os professores que não completassem seu padrão, nas horas livres, ministrassem aulas de recuperação, orientassem trabalhos de pesquisa em equipes ou, como no Rio Grande do Sul, constituíssem os "Clubes de Didática”, associações de diversas matérias do Curso Normal em que, sob a orientação de um professor, os alunos organizassem trabalhos de pesquisa nas disciplinas que precisavam ser recuperados. Ao fim, lista na bibliografia as obras Manual de Pedagogia Moderna e Enciclopédia de Pedagogia Labor, a Reforma do Ensino Normal do Rio Grande do Sul e, novamente nas orientações do setor de Assistência Técnica, Prática de Escola Serena, de Pilotto (PARANÁ, 1958e). 
O segundo e último texto também se preocupa com o caráter individual da educação, a questão da diferença de ritmos de aprendizados e, em alguma medida, aproxima-se da psicologia educacional. Armanda Sabino Lopes define "Orientação Educacional" como uma ação sistemática, com bases científicas, para assistir ao aluno em seu ajustamento social e desenvolvimento integral da personalidade, como conceituou o II Simpósio de Orientação Educacional (Porto Alegre). O escrito compreende-a como um "serviço que se realiza paralela e simultâneamente ao trabalho escolar", como uma ação permanente e constante. "Todo bom professor é um orientador" porque preocupado com o "desequilíbrio emocional" e “desajustamento”. A orientação educacional promove a integração do indivíduo ao grupo de pertencimento, ajusta o aluno às condições normais em seu lar, adapta-o às condições de vida escolar, promove o desenvolvimento harmonioso de sua personalidade para que se sinta feliz e realizado como estudante (PARANÁ, 1959a).

Embora a análise seja de fragmentos ou de textos completos do produzido pelo setor de Assistência Técnica do Serviço de Ensino Normal, a repetição de ideias, a sintonia entre eles, o forte vínculo com a pedagogia da Escola Nova, a contribuição do professorado feminino, em especial da Assistente Técnica Armanda Sabino Lopes, permite-nos análises provisórias, todavia substanciais.

\section{Considerações finais}

Na década de 1940 a 1960, em particular entre 1946 e 1961, que Miguel (1992) denomina como um período de expansão da Pedagogia Nova e do Curso Normal Regional, constata-se a dubiedade: enquanto os Cursos Normais Regionais do Paraná conviviam com o problema de espaço mínimo até para as aulas, este Estado assumiu a Escola Nova como uma política educacional, todavia abstendo-se de materiais pedagógicos e locais apropriados para concretização desta pedagogia, como também corrobora Faria (2017).

Entre 1949 e 1951, Erasmo Pilotto foi secretário da SEC e, mesmo com sua saída da pasta da educação, seu nome e suas ideias balizaram a formação de professores primários nos anos 1940 a 1960. Exemplar é a Revista de Pedagogia — órgão da Associação de Estudos Pedagógicos para os Cursos Normais Regionais, com 
significativo tempo de existência e extensiva produção, assim como a presença de citações e obras de Pilotto em materiais veiculados pela SEC, via SEN - no caso deste artigo, nos textos produzidos pelas Assistentes Técnicas.

No período investigado, a adoção de método ativo, o apelo ao trabalho com as instituições paraescolares, a persistência da realização de pesquisa na biblioteca denotam que a pedagogia nova foi tomada como política pública educacional paranaense e, para esta incumbência, foram eleitos educadores para atuarem conforme as premissas escolanovistas: Erasmo Pilotto e Diva Vidal. Preocupados com o âmbito da prática pedagógica, eles empreenderam ações para lidar com estes desafios e inovar e modernizar o campo educacional.

Pilotto, conhecedor do problema da escola primária rural e do professorado que atuava nestas instituições, com o caráter prescritivo da Revista de Pedagogia, enfatiza o processo de ensino individualizado e o uso do sistema de fichas, prática confirmada nos estudos de Hervatini (2011) e que sugere que as ideias prescritas nesta impressa pedagógica circulou nas Escolas Normais Regionais.

Tal análise está amparada em Julia (2001, p. 11), ao considerar as práticas prescritas a esse "[...] corpo profissional de agentes que são chamados a obedecer a essas ordens e, portanto, a utilizar dispositivos pedagógicos encarregados de facilitar sua aplicação, a saber, os professores primários e os demais professores" - em nosso estudo, professoras e professores primários que exerceram a docência nas Escolas Isoladas do meio rural paranaense.

Diante do cenário de expansão, da precariedade e da busca pela inovação pedagógica, Vidal cria mecanismos para que o "moderno" se interiorize. A presença de orientações do SEN em um Curso Normal Regional interiorano, como mostra Gonçalves (2016), prova que as iniciativas de Vidal adentraram-se em escolas de formação de professores primários, em particular, as rurais. Trata-se de iniciativas de sujeitos históricos que reverberaram em novas práticas, em sintonia com os novos tempos educacionais, a fim de "modernizar" o sertão paranaense.

\section{Referências}

AgUAYO, A. M. Didática da Escola Nova. Tradução e notas J. B. Damasco Penna e Antônio d’ Avila. 8. ed. São Paulo: Editora Nacional, 1952. (Atualidades Pedagógicas, v. 15). 
CAINELLI, M. R. Entre a roça e o ditado: a Campanha Nacional de Educação Rural Londrina: 1952/1963. 1994. Dissertação (Mestrado em História) — Universidade Federal do Paraná, Curitiba, 1994.

CAPELO, M. R. C. Educação, escola e diversidade cultural no meio rural de Londrina: quando o presente reconta o passado. 2000. 287f. Tese (Doutorado em Educação, Sociedade e Cultura) - Universidade Estadual de Campinas, Campinas, 2000.

FARIA, T. B. Paraná: território de "vocação agrícola"?! Interiorização do Curso Normal Regional (1946-1968). 2017. Tese (Doutorado em Educação) — Universidade Estadual de Maringá, Maringá, 2017. 1 CD-ROM.

GONÇALVES, A. L. P. O Ensino Normal Regional em Cianorte-PR: da institucionalização às práticas e saberes pedagógicos. 2016. Dissertação (Mestrado em Educação) — Universidade Estadual de Maringá, Maringá, 2016. 1 CD-ROM. (Documentos SEC 1955-1958; Documentos SEC 1959-1964).

HERVATINI, L. A Escola Normal Regional e suas práticas pedagógicas: dois retratos de um mesmo cenário no interior do Paraná. 2011. Dissertação (Mestrado em Educação) Universidade Estadual de Maringá, Maringá, 2011. Disponível em: <http://www.ppe.uem.br/dissertacoes/2011-Luciana-Hervatini.pdf>. Acesso em: 16 jun. 2015.

HOFF, S. A ocupação do norte. In: PAZ, F. (Org.). Cenários de economia e política - Paraná. Curitiba: Prephacio, 1991.

INSTITUTO PARANAENSE DE DESENVOLVIMENTO ECONÔMICO SOCIAL (IPARDES). O Paraná reinventado: política e governo. Curitiba: IPARDES, 1989.

JULIA, D. A cultura escolar como objeto historico. Revista Brasileira de História da Educação, n. 1, p. 9-44, jan./jun. 2001.

KOLODI, R. Áreas sociais desigualmente desenvolvidas pedem soluções pedagógicas diferenciadas. Revista de Pedagogia, Curitiba, v. IV, n. 2, p. 41-48, maio 1960.

MIGUEL, M. E. B. A pedagogia da escola nova no Paraná: início, consolidação e expansão do movimento. 1992. Tese (Doutorado em Educação) — Pontifícia Universidade Católica de São Paulo, São Paulo, 1992.

MORTATTI, M. R. L. Os sentidos da alfabetização (São Paulo/ 1876-1994). 2. reimp. São Paulo: Editora UNESP, 2000. (Encyclopaidéia).

OLIVEIRA, D. Urbanização e industrialização no Paraná. Curitiba: SEED, 2001. (Coleção História do Paraná: textos introdutórios). Disponível em: <http://www.humanas.ufpr.br/portal/historiapos/files/2011/05/Urbaniza\%C3\%A7\%C3 $\%$ A3o-e-Industrializa $\% C 3 \% A 7 \% C 3 \%$ A3o-no-Paran $\% C 3 \% A 1 . p d f>$. Acesso em: 04 jul. 2016.

PARANÁ. Decreto no 19.891, de 02 de dezembro de 1955. Aprova a Regulamentação das Escolas Normais das Bases da Organização do Ensino Normal. Diário Oficial do Estado, Curitiba, n. 221, dez. 1955. 
PARANÁ. Decreto no 17.503 de 23 de junho de 1958. Aprova a regulamentação e organização do Ensino Normal do estado. Diário Oficial do Estado, Curitiba, n. 102, jun.1958a.

PARANÁ. Secretaria de Educação e Cultura. Serviço de Ensino Normal. Como conseguir pontualidade dos alunos nos trabalhos práticos. Curitiba: SEC, 1958b.

PARANÁ. Secretaria de Educação e Cultura. Serviço de Ensino Normal. Considerações sôbre o caráter prático dos programas de Português e Matemática - E.N.R. Curitiba: SEC, 1958c.

PARANÁ. Secretaria de Educação e Cultura. Serviço de Ensino Normal. Orientação geral sôbre parte do programa de Música das Escolas Normais Regionais. Curitiba: SEC, 1958d.

PARANÁ. Secretaria de Educação e Cultura. Serviço de Ensino Normal. Orientação para recuperação de alunos das Escolas Normais. Curitiba: SEC, 1958e.

PARANÁ. Secretaria de Educação e Cultura. Serviço de Ensino Normal. Orientação sôbre Estudos Dirigidos. Curitiba: SEC, $1958 \mathrm{f}$.

PARANÁ. Secretaria de Educação e Cultura. Serviço de Ensino Normal. Orientações sôbre Profilaxia da cola - Escolas Normais Regionais e Secundárias. Curitiba: SEC, 1958g.

PARANÁ. Secretaria de Educação e Cultura. Serviço de Ensino Normal. Ofício. Curitiba: SEC, 1958h.

PARANÁ. Secretaria de Educação e Cultura. Serviço de Ensino Normal. Conceito de Orientação Educacional e valor da mesma nos Cursos Normais. Curitiba: SEC, 1959a.

PARANÁ. Secretaria de Educação e Cultura. Serviço de Ensino Normal. Programa de Higiene, Ciências Físicas e Naturais. Curitiba: SEC, 1959b.

PARANÁ. Secretaria de Educação e Cultura. Serviço de Ensino Normal. Trabalho em grupo. Curitiba: SEC, 1959c.

PARANÁ. Secretaria de Educação e Cultura. Serviço de Ensino Normal. Circular $n^{0} 21$ Assistência Técnica do S.E.N. Curitiba: SEC, [1958 ou 1959a].

PARANÁ. Secretaria de Educação e Cultura. Serviço de Ensino Normal. Informações sôbre a organização dos Grêmios Escolares. Curitiba: SEC, [1958 ou 1959b].

PARANÁ. Secretaria de Educação e Cultura. Serviço de Ensino Normal. Material funcional nas aulas práticas. Matéria de Didática. Curitiba: SEC, [1958 ou 1959c].

PARANÁ. Secretaria de Educação e Cultura. Serviço de Ensino Normal. Orientação sôbre as reuniões mensais. Curitiba: SEC, [1958 ou 1959d].

PARANÁ. Secretaria de Educação e Cultura. Serviço de Ensino Normal. Plano de curso e de aula. Curitiba: SEC, [1958 ou 1959e].

PARANÁ. 50 anos da Secretaria de Estado da Educação: 1947-1997. Curitiba: SEED, [1997?].

PILOTTTO, E. A educaşão é direito de todos. Curitiba, 1952. 
PILOTTO, E. A educação em sociedade em desenvolvimento. Revista de Pedagogia, Curitiba, v. IV, n. 2, p. 49-58, maio 1960a.

PILOTTO, E. Revista de Pedagogia, Curitiba, v. I, n. 1, maio 1957, p. 1-11.

PILOTTO, E. Um plano nacional de combate ao analfabetismo. Revista de Pedagogia, Curitiba, v. IV, n. 2, p. 31-41, maio 1960b.

SCHELBAUER, A. R. Entre anúncios e artigos. Registros do método de ensino intuitivo no jornal A provincia de São Paulo (1875-1889). In: ARAÚJO, J. C.; SCHELBAUER, A. R. (Orgs.). História da Educaşão pela Imprensa. Campinas: Alínea, 2007. p. 7-30.

SCHELBAUER, A. R. Da roça para a escola: institucionalização e expansão das escolas primárias rurais no Paraná (1930-1960). Hist. Educ. [Online], v. 18, n. 43, p. 71-91, maio/ago. 2014. Disponível em: <http://www.scielo.br/pdf/heduc/v18n43/05.pdf>. Acesso em: 17 ago. 2016.

SCHELBAUER, A. R.; GONÇALVES NETO, W. Ensino primário no meio rural paranaense: em foco as Escolas de Trabalhadores Rurais e de Pescadores entre as décadas de 30 e 50 do século XX. Cadernos de História da Educação, v. 12, n. 1, p. 83-107, jan./jun. 2013. Disponível em: <http://www.seer.ufu.br/index.php/che/article/view/22898/12471>. Acesso em: 17 ago. 2016.

SILVA, R. Revista de Pedagogia e sua concepção de ensino para a educação paranaense (1957 a 1966). Acta Scientiarum. Education, v. 40, p. 1-10, 2018.

TOMAZI, N. D. "Norte do Paraná": História e fantasmagorias. 1997. Tese (Doutorado) — Universidade Federal do Paraná, Curitiba, 1997.

VIDAL, D. H. (Org.). Secretaria de Educação e Cultura. Relatório do $2^{\circ}$ Semestre do Serviço do Ensino Normal. Curitiba: Serviço de Ensino Normal, 1958.

VIEIRA, C. E. Educação e modernidade no projeto formativo de Erasmo Pilotto. 2006. Disponível em: <http://www.sbhe.org.br/novo/congressos/cbhe4/coordenadas/eixo06/Coordenada $\% 2$ 0por $\% 20$ Carlos $\% 20$ Eduardo $\% 20$ Vieira/Carlos $\% 20$ Eduardo $\% 20$ Vieira $\% 20$ -

\%20Texto.pdf>. Acesso em: 31 dez. 2015.

VIEIRA, C. E. O movimento pela Escola Nova no Paraná: trajetória e idéias educativas de Erasmo Pilotto. Educar, Curitiba, n. 18, p. 53-73, 2001. Disponível em: <http://www.scielo.br/pdf/er/n18/n18a06.pdf>. Acesso em: 31 dez. 2015.

RECEBIDO: 01/06/2019

APROVADO: 05/06/2019
RECEIVED: 06/01/2019

APPROVED: 06/05/2019
RECIBIDO: 01/06/2019

APROBADO: 05/06/2019 